Journal of Universal Language 13-2

September 2012, 65-89

\title{
Sound Change in Deori: A Descriptive Account
}

\author{
Arup Kumar Nath \\ Tezpur University
}

\begin{abstract}
This paper deals with the sound changes that have undergone in Deori language from the time of publication of Grierson's Linguistic Survey of India, i.e., 1903 to the present time. (That is till the time of collecting data: January 2008 - January 2009.) During this span of hundred and five years, a considerable amount of phonetic and morphological changes have taken place. Deori has shown ample evidences of sound changes in the patterns of complete lexical shift, epenthesis, devoicing, de-aspiration, vowel shift, nasalization, elision, deletion, morpheme addition, degemination, borrowing, and so on. Most remarkably the loan and borrowing words are fast replacing the basic vocabularies of this language.
\end{abstract}

Keywords: lexicon, shift, sound change, Tibeto-Burman

\footnotetext{
Arup Kumar Nath

Center for Assamese Studies

School of Humanities and Social Sciences, Tezpur University, Assam, India

Phone: +919864196993; Email: arupjnu@gmail.com
}

Received August 29, 2011; Revised August 23, 2012; Accepted September 3, 2012. 


\section{Introduction}

In this paper, an attempt is made to describe sound changes that have taken place in Deori language in the last hundred years. Rather than forming sound change rules, the paper would focus more in the description of sound changes which are found to be operational in this language. Deori, a Sino Tibetan language, is a daughter language of Bodo group of Tibeto-Burman language family which is also known as the Chutiya language. This language was earlier known as Deori Chutiya or Chutiya. Deori is spoken mostly in the Upper Assam areas of India especially in the districts of Lakhimpur, Dhemaji, Dibrugarh, Sibsagar, Jorhat, Majuli, Tinsukia, and eastern part of Sonitpur district. The Ethnologue has figured approximately 26,9001 speakers for this language. About this language Grierson (1903: 118) remarks, "The Chutiya language, indeed, may fairly claim to be the original language of Upper Assam." Although the vocabulary of this language is influenced by the Naga dialects due to its close juxtaposition, as noticed by Grierson, the Assamese language has also contributed a lot to its vocabulary. In this context Brown (1895) commented, "Indeed, it has recently been officially announced to be extinct by the author of the Assam Census Report for 1891. This is by no means the case; for although the Deoris all speak Assamese fluently, and have incorporated a good many Assamese words in their own vocabulary, still they all speak their own language; and rather proud of it, and of the difficulty of learning it."

The Deori phonology has allowed seventeen consonants and five vowels at segmental level. At tonal level, two tones have been recognized. The consonants are: (a) Plosives: p, t, k, b, d, g, (b) Nasals: n, m, y, (c) Fricatives: s, z, h, (d) Affricate: ts, (e) Lateral: 1 (tap or flap) r, (f) Semi Vowels: v, j. Similarly, the Deori

1 http://www.ethnologue.com/show_language.asp?code=der (Date: March 30, 2012) 
language has five vowel sounds viz. i, u, e, o, e. Like many Tibeto-Burman languages, words which are ending with consonant sound are always invariably the palatal nasal $/ \mathrm{y} / \mathrm{such}$ as $\sin$ (iron), libin (man), an (I), and so on whereas, the basic feature of the words is vowel ending words such as $\mathrm{k}^{\mathrm{h}} \mathrm{u}$ (mouth), ma (mother), margi (woman), and so on. The basic Deori word order is SOV. Participialization is done by adding some particular suffixes such as 'wa,' 'ba' or 'ma' with the verbs. The Deori Morphology mostly agglutinative with each affix represents one unit of meaning. Different affixes like 'ma,' 'ba,' 'ne' are found to have added to the verbal and nominal roots to form nouns, adjectives, and verbs.

\section{Theoretical Perspectives of Sound Change}

Sound Change is a phonological process which is usually accepted by almost all the speakers of a language. It is a universal and regular phenomenon occurs in all human languages. Languages undergo changes at all linguistic levels, i.e., at phonemic, morphological, syntactic, and semantic levels. The language changes are triggered by various reasons. A language may split into two or more languages if the speakers get separated into two or more groups with little or no contact. For example, Spanish, Portuguese, Catalan, and so on, i.e., the Romance languages are the result of a Latin people being scattered away in different regions of Europe. Another important reason is the 'language contact' which plays immense role in language change. If two groups of people speaking two different languages (possibly mutually not intelligible) come to close contact with each other then each group's language may begin to adopt features of the other's. Vocabulary is frequently added to a language through language contact. Labov (2001), in fact, observes that all linguistic changes 
are motivated by some social factors, not always by phonetic factors. Apart from these two causes 'borrowing' also plays a pivotal role in language change. The changes not necessarily be always unidirectional, they can be operational in various directions.

The phenomena of sound changes are being studied on the backdrop of two hypotheses: (i) The Regularity Hypothesis and (ii) The Neogrammarian Hypothesis. The Regularity Hypothesis considers that "Regular changes recur generally and take place uniformly wherever the phonetic circumstances in which the change happens are encountered. To say that a sound change is a regular means that the change takes place whenever the sound or sounds which undergo the change are found in the circumstances or environments that condition the change." (Campbell 2004: 17). Although Neogrammarians school of thought believes that 'sound laws suffer no exception' (Osthoff \& Brugmann 1878), there are lots of exceptions. Labov (1981: 268, 1994: 422) had clearly stated that Neogrammarian Hypothesis which is also known as sound change law is 'perhaps the most clearly stated issue' in the history of linguistics.

Even after drawing some criticism, the sound change rules have never lost their appeal in the synchronic and diachronic study of sound change. For instance, the loss of sound is a focal point in the historical linguistics. It doesn't necessarily imply the weakening of speech sounds. It occurs in other environment as well. The loss of $/ \mathrm{k} /$ sound before nasals in English, for example in the English word 'knowing' [øn], adequately proves the operation of sound loss in the evolution of this language. Therefore, sound loss is also a form of sound change. Secondly, many a time due to the lengthening of a preceding vowel, the phenomenon of sound loss occurs. Epenthesis is another sort of sound change which is in fact ubiquitous in many Indian languages. In this process, the speakers tend to insert speech sounds in the words. The most popular example in Indian context is the insertion of /i/ sound in the word 'school' [iskul]. Moreover, 
"A common subtype of epenthesis consists of the insertion of vowels before word initial consonant groups or into such groups elsewhere. A well known example is the process of Prothesis in early Spanish and French, which inserted an [e] in front of $\mathrm{s}+$ stop clusters." (Hock \& Joseph 1996: 131). This process also allows consonant insertion.

Hock (1991: 2) opines that "language change is not a completely random, unprincipled deviation from a state of pristine perfection, but proceeds in a large measure in a remarkably regular and systematic fashion, without any profound effects on our ability to communicate." Rask and Grimm in their studies on Sound Change did not expect that the changes would be so regular (Hock \& Joseph 1996: 118). In the words of Hock \& Joseph (ibid.), "they were too much influenced by the idealism of the Romantic movement to believe that human beings were capable of behaving with complete, exceptionless regularity, as if they were automata or machine." The group of young linguists from Leipzig, Germany who were labeled as Neogrammarians, after extensive study of Grimm's hypothesis, were in the opinion that Sound Change is not just 'overwhelmingly regular' or like that, but they are 'absolutely regular.' In fact, in another note, the assumption operates blindly. "An understanding of sound change is truly important for historical linguistics in general, and this needs to be stressed-it plays extremely important role in the comparative method and hence also in linguistic reconstruction, in internal reconstruction, in detecting loanwords, and determining whether languages are related to one another (Campbell 2004: 16)."

\section{Approach toward Language Change}

It is said that the older generation always preach their spoken form to be preserved and believe that theirs is the pure and 
pristine form of language or they would claim some of the structure or coinage used by the new generation speakers are totally unacceptable and ungrammatical. The author has personally come across many articles and complains being published in Assamese dailies that a group of people above a certain age level are not comfortable with many new coinage and syntactic structure of Assamese that is being used by the young speakers of the language. It is also pertinent to note that some administrative authorities or the literary organizations are formed and entrusted them to translate and recreate various technical terms in their respective languages so that a kind of coherence in language use could be maintained. The Assam Sahitya Sabha of Assam, Sahitya Academy, the Directorate of Hindi, Commission for Scientific and Technical Terminology under the Ministry of Human Resource Development, India, and so on are some examples of governmental and non-governmental institutions whose suggestions are given utmost importance in the standardization of language use. But, it is always in the hands of actual speakers who give direction or a shape to a language. Therefore, change is likely to occur in any circumstances.

\section{Description of Deori Sound Changes}

\subsection{Grierson as the Source}

Although Sir George Abraham Grierson's work has both merits and demerits, considering the age and time period when this daunting project was undertaken, this compilation could be considered the only substantial, holistic, and synchronic study of almost all Indian languages and their major varieties. These mammoth volumes of linguistic works were published during the period of 1894 to 1927. In this paper data are taken from 
Linguistic Survey of India, Volume 3 (Part 2): Tibeto-Burman Family (Grierson (ed.) 1903), and those data are being compared with the present Deori data.

\subsection{Evidences for Sound Change in Deori}

Sound change is a universal phenomenon of all languages. Hence, Deori language also accounts instances of sound changes. The following one is an attempt to check the observable sound changes in Deori at lexical and phonetic levels on the basis of Grierson's data and the data collected by the author. However, the paper restricts itself in the discussion of only those processes where Deori examples are encountered. Linguistic evidence is an important source of information about the past. In case of Deori language, the borrowing words from Assamese rightly assert the dominance of Assamese on it. Moreover, the age long cultural relationship from time immemorial between the people of this community and the surrounding speech communities such as Assamese, Bengali, Arunachali tribes, and so on could also be inferred from the lexicon of this language. Jay Jasanoff has rightly commented that "although linguistic evidence can lead us to set up temporally remote protolanguages, the translation of linguistic relationship into real time history is a hazardous enterprise."2

\subsection{Observable Sound Changes in Deori}

Deori language had the evidences of using its entire number system long time ago. It is still found in some written documents of this language. But, unfortunately, the present speakers cannot remember the numerals barring first two/three numbers. Some of numerals are still retained only in the speech of handful old aged speakers of this community. And those which are still in use have

$2 \mathrm{http} / /$ www.people.fas.harvard.edu/ jasanoff/historical_linguistics.html 
undergone drastic changes over the period of last hundred years. At the same time, some of them have still retained their old phonemic forms. Let us examine the numerals which are still in use.
(1) one
Grierson $(1903)^{3}$
Deori $(2009)^{4}$
(2) three
$m u-n g d a$
muja
munda

The first two examples have not seen any changes in this period of time. But the word muhuni (example (3)) denoting two sees sound changes in different environments. Firstly, the voiceless glottal fricative $/ \mathrm{h} /$ becomes voiceless velar fricative $/ \mathrm{x} /$ and the shift from back vowel $/ \mathrm{u} /$ to front vowel $/ \mathrm{i} /$ is evident. There is enough possibility of this kind of sound change being inflicted by Assamese. It's because of the extensive presence of the velar fricative $/ \mathrm{X} /$ in Assamese sound system.
(3) two
$\frac{\text { Grierson }}{\text { muhuni }}$
$\underline{\text { Deori }}$
$\mathrm{h} \rightarrow \mathrm{x} / \mathrm{V}_{-} \mathrm{V}$ and
$\mathrm{u} \rightarrow \mathrm{i} / \mathrm{C}_{-} \mathrm{C}$
muxini

The Grierson's data show that numerals till nine are formed with the addition of morpheme $m u$ as prefix. But the current data reveal that after three this morpheme mu got lost somewhere during this 100 years span.
(4) four
$\frac{\text { Grierson }}{m u \text {-chil }}$
$\frac{\text { Deori }}{\mathrm{c}^{\mathrm{h}_{\mathrm{i}}}}$
$\mathrm{mu} \rightarrow \varnothing, 1 \rightarrow \varnothing /{ }_{-} \#$

3 IPA is not used in Grierson's data as they were given in Roman script in the original book.

4 Deori, Chandra. Singh(Deori Informant), Age: 81 (10+2), Date: January 22, 2009 
In the following instance, the voiced alveolar fricative has lost its aspiration property during this period of time. If that is not the case, this feature could be attributed as the regional variation of Deori.
(5) $\underline{\text { Gloss }}$
Grierson
mu-shing
$\mathrm{s}^{\mathrm{h}} \rightarrow \mathrm{s} / \#$ _ V
Deori
$\sin$

Apart from the morpheme loss, the naming of Deori numeral has also shown the evidence of apocope where the final sound of a word usually gets lost. In the above instance, i.e., in (example (4)) $c^{h} i$ the loss of lateral $/ 1 /$ is the classic example of apocope.
(6) five
$\underline{\text { Grierson }}$
$\underline{\text { Deori }}$
moi
$\mathrm{mu} \rightarrow \varnothing$, oa $\rightarrow$ oi/C_\#

The notion of Correspondence theory of diphthong alteration developed by MaCarthy \& Prince accounts that "given two strings $\mathrm{S} 1$ and $\mathrm{S} 2$, correspondence is a relation $\mathrm{R}$ from the elements of $\mathrm{S} 1$ to those of S2. Elements A of S1 and B of S2 are referred to as correspondents of one another when A $R$ B" (MaCarthy \& Prince 1993, cited in Kikuchi 1997: 40). In Deori, (example (6)) when the diphthong $o a$ has changed into $\partial i$, following the rules of correspondence, the close-mid back vowel turns to an open-mid back and the front open vowel changes to a front close vowel.
(7) $\frac{\text { Gloss }}{\operatorname{six}}$
$\frac{\text { Grierson }}{m u-c h a a}$
$\frac{\text { Deori }}{\mathrm{c}^{\mathrm{h}} \mathrm{u}}$
$\mathrm{mu} \rightarrow \emptyset, \mathrm{a} \rightarrow \mathrm{u} / \mathrm{C}_{-} \#$
(8) eight
mu-shi
se
$\mathrm{mu} \rightarrow \emptyset, \mathrm{i} \rightarrow \mathrm{e} / \mathrm{C}_{-} \#$ 
In the above evidences where, $a \rightarrow u$ and $i \rightarrow e$ the phenomena of vowel raising and vowel lowering have occurred. In the first instance the front low open vowel has been raised towards the back high close position and in the other example change has taken place by lowering the high back close vowel to the front mid close vowel.

In Deori, evidences of elision, where the speakers tend to lose the unstressed sounds, are also found. For example (in (9) and (10)) the loss of /d/ sounds has occurred due to the positioning of unstressed sounds.
(9) $\frac{\text { Gloss }}{\text { nine }}$
$\underline{\text { Grierson }}$
$\underline{\text { Deori }}$
$\mathrm{mu} \rightarrow \varnothing, \mathrm{d} \rightarrow \varnothing / \mathrm{V}_{-} \mathrm{V}$
(10) ten
$d g a$
$\mathrm{d} \rightarrow \emptyset / \#+\mathrm{V}$
gu
ga

But in numerals twenty and fifty, it is seen that there is a complete shift of lexical items from Grierson's time to present time, while in hundred the aspirated $/ \mathrm{k}^{\mathrm{h}} /$ has lost its property of aspiration over this period of time.
(11) $\frac{\text { Gloss }}{\text { twenty }}$
Grierson
$\underline{\text { Deori }}$
khua-cha
miga
Complete lexical shift
(12) fifty
khuaakni otu pekini
munda
Complete lexical shift
(13) hundred

$$
\text { khuaa moaa }
$$ $\mathrm{k}^{\mathrm{h}} \rightarrow \mathrm{k} / \# \mathrm{~V}$
kuamua

The confusion in the analysis of the numeral words represented 
for three and fifty which show identical words for both the numerals, has made the analysts pause for a moment. Similarly, the analysis of twenty also does not bring into any logical conclusion. If we go by the analysis of the word for hundred which is kuamua we can assume that it stands for $20 * 5=100$. Since Grierson has given khua-cha for twenty and moa for five, we can safely assume that the present word for twenty in Deori would be either kua or khua (even if we argue that it has not undergone any sound change during this period).

In the literature on lexical access, it has been found that word recognition is influenced by the frequency of the word, its neighbor, and by semantic priming (Lehrer 1996: 366). A word needs more time to be understood if there exist many words (neighbors) that resemble it phonetically (or orthographically). Neighboring words are activated when the word is heard. Not only high neighborhood density but also high neighborhood frequency may impede access to words (Luce et al. 1990). Word recognition is facilitated by the Semantic Priming. If the words heard belong to the same semantic field, they will be more readily understood than if heard in isolation. So it can be assumed that frequency, neighborhood density, and semantic priming play immense role in adopting and shifting toward new lexical items. New lexical items are the invention of time and initially they are spontaneously coined but their usage is less. Once they reach the status of neologism among the speakers of a language, they will start affecting the language by bringing changes to the system. For instance, developments on the level of the language norm can give rise to word elements (e.g., affixes or combining forms) which become productive and lead to new word formation patterns in the language system. Changes on the level of parole, through the level of norm, may result in changes at the system level. The neologism develops from a diachronic process; the common vocabulary is a synchronic abstraction (Fischer 1998: 5-6). Deori language has seen a great transformation of lexical shift in due course of time. 
This has not happened overnight. It took years to shift to a new item, then getting it familiarized and accepted by the speakers of this language. In many lexical shifts, it was not merely phonotactic changes; the semanticity was also associated with those shifts. Let us see the words where the lexicons of Grierson's time have undergone Complete Lexical Shift in Deori. Deori has enumerated a whole lot of words which have undergone complete lexical shift in due course of time. These shifts are completely sporadic in nature and follow no phonetic rules or patterns. They can be also called the result of internal development of sound change.

\begin{tabular}{|c|c|c|c|}
\hline & $\underline{\text { Gloss }}$ & Grierson & Deori \\
\hline (14) & a. twenty & $\overline{k h u a-c h a}$ & $\overline{\text { miga }}$ \\
\hline & b. fifty & khuaakni otu pekini & munda \\
\hline & c. you & loru & no \\
\hline & d. ear & yiaakhung & aku \\
\hline & e. father & chipaa & ban, baba \\
\hline & f. mother & chima & ijoy, ijəi \\
\hline & g. brother & chimu, chipu & kai (elder), goi (younger) \\
\hline & h. sister & chibi, pishia & bai (elder), be (younger) \\
\hline & i. god & midi & kundigira \\
\hline & j. house & nyo, aacho & iyã \\
\hline & k. beat & $b u-b e$ & boroba \\
\hline & 1. near & buliga, lugunga-ha & haduhs \\
\hline & m. behind & imaru & simiho, simipe \\
\hline & n. alas & dehi $a i$ & ayoh \\
\hline & o. their & niyo & bars \\
\hline & p. yours & loriyo & noro \\
\hline & q. of you/your & loriyo & nio \\
\hline & r. but & kintu & dasia \\
\hline & & $\begin{array}{l}\text { Complete lexical shi } \\
\text { Assamese borrowing }\end{array}$ & $\mathrm{ft}$, but kintu is an \\
\hline & s. they & baaro & bou \\
\hline & t. your & loriyo & nois \\
\hline
\end{tabular}


The following diagram would display that out of all hundred words being considered for sound change in Deori, $20 \%$ of words are found to have embraced new lexicons, i.e., the phenomenon of Complete Lexical Shift has been recorded. The Grierson bar in the diagram stands for total amount of words subjected for experimentation.

Figure 1. Percentage of Complete Lexical Shift

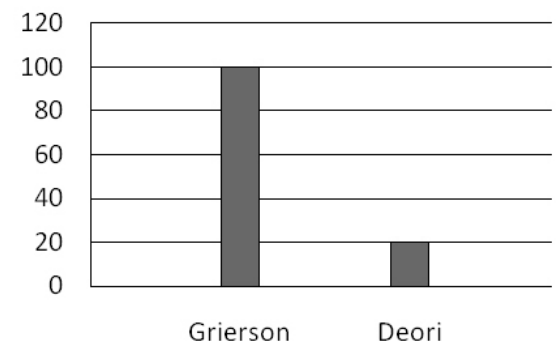

Deori language has also accounted occurrence of Epenthesis where speakers tend to introduce a new sound in between two adjacent sounds. Epenthesis is one of the most regular phenomena of sound changes. In case of the excrescence the inserted sound must be a consonant, while in anaptyxis the sound has to be a vowel sound. Deori examples of epenthesis are given bellow where the data have shown that Deori has come across only excrescence type of epenthesis.
(15) $\frac{\text { Gloss }}{\text { give }}$
$\frac{\text { Grierson }}{\text { laie-be }}$
$\underline{\text { Deori }}$
$\mathrm{e} \rightarrow \mathrm{a} / \mathrm{C}_{-} \#$ and $/ \mathrm{r} /$ insertion; hence excrescence
(16) far
aachaai
asaho
$\mathrm{c}^{\mathrm{h}} \rightarrow \mathrm{s} / \mathrm{V}_{-} \mathrm{V}, / \mathrm{h} /$ insertion; hence excrescence
$\mathrm{ai} \rightarrow \mathrm{s} / \mathrm{V}_{-}$\# 
The present grammarians and linguists from the Deori community unanimously opine that Deori language had never experienced aspiration in any circumstances. But, the Grierson's data have revealed that earlier aspiration had been a part of Deori phonology. Since, intervocalic voicing is a common pattern of sound change in many languages Deori has also shown instances of deaspiration. During this period of more than hundred years, some aspirated sounds have lost their aspiration property. The data clearly extrapolate that over this period of hundred years this language has lost aspiration in all position of sounds viz. in initial, medial, and final syllabic positions.

\begin{tabular}{|c|c|c|c|}
\hline (17) & $\frac{\text { Gloss }}{\text { seven }}$ & $\begin{array}{l}\frac{\text { Grierson }}{\text { mu-shing }} \\
\mathrm{s}^{\mathrm{h}} \rightarrow \mathrm{s} / \#+\mathrm{V}\end{array}$ & $\frac{\text { Deori }}{\sin }$ \\
\hline (18) & eight & $\begin{array}{l}m u-s h i \\
\mathrm{mu} \rightarrow \varnothing, \mathrm{s}^{\mathrm{h}} \rightarrow \mathrm{s} / \# \_\mathrm{V},\end{array}$ & $\begin{array}{l}\mathrm{se} \\
\mathrm{i} \rightarrow \mathrm{e} / \mathrm{C}_{-} \#\end{array}$ \\
\hline (19) & hundred & $\begin{array}{l}\text { khuaa moaa } \\
\mathrm{k}^{\mathrm{h}} \rightarrow \mathrm{k} / \#+\mathrm{V}\end{array}$ & kuamua \\
\hline (20) & iron & $\begin{array}{l}\text { shing } \\
\mathrm{s}^{\mathrm{h}} \rightarrow \mathrm{s} / \# \text { V V }\end{array}$ & $\sin$ \\
\hline (21) & nose & $\begin{array}{l}\text { guthung } \\
\mathrm{t}^{\mathrm{h}} \rightarrow \mathrm{t} / \mathrm{V}_{-} \mathrm{V}, \mathrm{g} \rightarrow \varnothing / \mathrm{V}_{-} \neq\end{array}$ & gutũ \\
\hline (22) & hair & $\begin{array}{l}\text { khing } \\
\mathrm{k}^{\mathrm{h}} \rightarrow \mathrm{k} / \# \_\mathrm{V}\end{array}$ & kin \\
\hline (23) & belly & $\begin{array}{l}\text { uthung } \\
\mathrm{t}^{\mathrm{h}} \rightarrow \mathrm{t} / \mathrm{V} \text { V }\end{array}$ & utun \\
\hline
\end{tabular}


(24) man

mashi

mosi

$\mathrm{s}^{\mathrm{h}} \rightarrow \mathrm{s} / \mathrm{V}_{-} \mathrm{V}$

(25) woman

mishigu

$\mathrm{s}^{\mathrm{h}} \rightarrow \mathrm{S} / \mathrm{V}_{-} \mathrm{V}$

(26) child

mausha

$\mathrm{s}^{\mathrm{h}} \rightarrow \mathrm{S} / \mathrm{V}_{-} \mathrm{V}$

(27) gold

phuji

$\mathrm{p}^{\mathrm{h}} \rightarrow \mathrm{p} / \mathrm{\#} \_\mathrm{C}$

misigu-mosi

(28) son

pisha

$\mathrm{s}^{\mathrm{h}} \rightarrow \mathrm{s} / \mathrm{V}_{-} \mathrm{V}$

mausa

puji

(29) daughter

pishassi

$\mathrm{s}^{\mathrm{h}} \rightarrow \mathrm{s} / \mathrm{V}_{-} \mathrm{V}$

pisasi

(30) dog

shi

$\mathrm{s}^{\mathrm{h}} \rightarrow \mathrm{s} / \#$ V

pisa

(31) ass

gaadha $\mathrm{d}^{\mathrm{h}} \rightarrow \mathrm{d} / \mathrm{V}_{-} \mathrm{V}$

si

khero keruba

(32) go

$\mathrm{k}^{\mathrm{h}} \rightarrow \mathrm{k} / \#+\mathrm{V}, \mathrm{o} \rightarrow \mathrm{u} / \mathrm{C}_{-} \mathrm{C}, / \mathrm{ba} /$ addition

(33) come

khu-be koba

$\mathrm{k}^{\mathrm{h}} \rightarrow \mathrm{k} / \#$ _C, u $\rightarrow$ o/C_C, e $\rightarrow \mathrm{a} / \mathrm{C}$ \#

(34) stand

thekaa-be tagaba

$\mathrm{t}^{\mathrm{h}} \rightarrow \mathrm{t} / \#+\mathrm{V}, \mathrm{e} \rightarrow \mathrm{a} / \mathrm{C}_{-} \mathrm{C}, \mathrm{k} \rightarrow \mathrm{g} / \mathrm{V}_{-} \mathrm{V}, \mathrm{e} \rightarrow \mathrm{a} / \mathrm{C}_{-} \#$ 
(35) down

$$
\begin{aligned}
& \text { khumaa-ba } \\
& \mathrm{k} \mathrm{h} \rightarrow \mathrm{k} / \#+\mathrm{V}, \mathrm{a} \rightarrow \mathrm{i} / \mathrm{C}_{-} \mathrm{C}, \mathrm{b} \rightarrow \mathrm{h} / \mathrm{V}_{-} \mathrm{V}, \mathrm{a} \rightarrow \mathrm{o} / \mathrm{C}_{-} \#
\end{aligned}
$$

Some of the instances also exhibit evidences of nasalization in Deori. Usually, a vowel sound tends to get nasalized when it occurs near a nasal consonant. John Ohala in his proposal to vowel nasalization defines that "vowel nasalization is a low-level phonetic process outside the grammar that occurs in the environment of a nasal consonant. As long as the nasal consonant is still perceived to be present, this nasalization will be factored out by the listener. However, once N-deletion has transpired, the nasalized vowels are phonemicized and can then be treated as contrastive in the language. After N-deletion, the nasalization of the vowel will also be exaggerated. In this model the whole process can be summarized in two steps: /vn/ > / vn/ $>/ \tilde{\mathrm{v}} /$." (Ohala 1981: 186, 1988: 15-16, cited in Klopfenstein 2006: 6-7). Similarly, in Deori language, (36) the nasalization of gutũ supports the above condition and hence it is a case of assimilation where it explicitly loses the nasal sound. By following this rule it can be assumed that in the word (37) where otu $\rightarrow u t \tilde{u}$, the nasal sound must have lost its position or got assimilated with the vowel through the nasalization process.

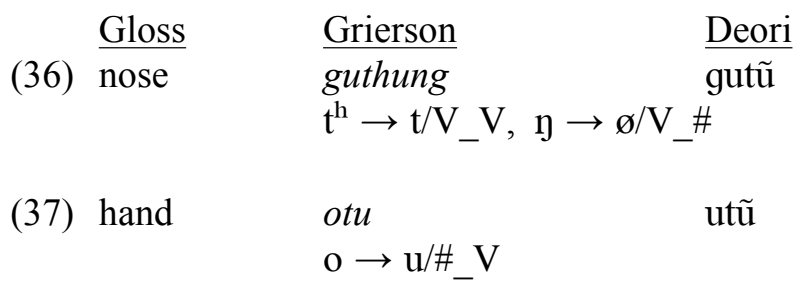

Degemination ((39), (40)) process occurs to simplify or make a sound more natural. Deori language shows the evidences of degemination where nasal consonants $/ \mathrm{mm} /$ gets degeminated by dropping one $/ \mathrm{m} /$ sound in the word daammai and two alveolar 
fricatives become a single $/ \mathrm{s} /$ in the word Pishassi.
a. dammai $[\mathrm{mm}]$
$\mathrm{m} \rightarrow \varnothing$
damai
b. pishassi [ss]
$\mathrm{S} \rightarrow \varnothing$
pisasi

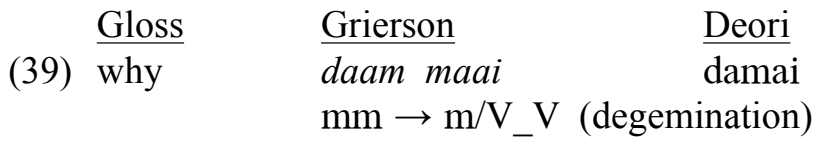

(40) daughter pishassi pisasi ss $\rightarrow$ s/V_V (degemination)

One of the most common operations of sound change in Deori has been the loss of morpheme in due course of time. Beck (2006: 494) pointed out that "a morphological ellipsis is an ellipsis which is applicable only within the limits of a word form." Morphological ellipsis is triggered by morphological incompatibility. Morphological truncation is also a similar operation to ellipsis, but the only difference between them is that ellipsis is always meaningless, but truncation can be both, i.e., meaningful or meaningless. The zero sign is also a kind of ellipsis, but it has to be a meaningful one. The loss of morphemes can be anywhere irrespective of their positions. To simplify the morphological pattern, speakers of a language tend to drop some bound morphemes from the words. Since all the speakers of Deori are bilingual with equal proficiency in Assamese, they are more vulnerable to lose the bound morphemes. In Deori numeral system, the loss of $/ \mathrm{mu} /$ morpheme stands out prominently. 
82 Sound Change in Deori: A Descriptive Account
(41) we
Grierson Deori
jaaru, jaruaa jou
$\mathrm{a} \rightarrow$ ou, ru/rua $\rightarrow$ ø/_\#
(42) cultivator
ogaатиаa
mua
oga $\rightarrow \varnothing$
(43) $\operatorname{cock}$
dufa
$\mathrm{du}$
$\mathrm{fa} \rightarrow \varnothing / \#$

(44) slave

mira, miraisi

miro

$\mathrm{a} \rightarrow \mathrm{o} / \mathrm{C}_{-} \#$, /isi/ deletion

(45) four

$$
\begin{aligned}
& \text { mu-chil } \\
& \mathrm{mu} \rightarrow \varnothing, 1 \rightarrow \varnothing / \ldots
\end{aligned} \quad \mathrm{c}^{\mathrm{h}_{\mathbf{i}}}
$$

(46) five

mu-moa moi

$\mathrm{mu} \rightarrow \varnothing$, oa $\rightarrow$ oi $/ \mathrm{C}_{-} \#$

(47) seven

$$
\begin{aligned}
& \text { mu-shing } \\
& \mathrm{mu} \rightarrow \varnothing, \mathrm{d} \rightarrow \varnothing / \mathrm{V}_{-} \mathrm{V}^{\mathrm{sin}}
\end{aligned}
$$

(48) eight

$$
\begin{aligned}
& m u-s h i \\
& \mathrm{mu} \rightarrow \varnothing, \mathrm{s}^{\mathrm{h}} \rightarrow \mathrm{s} / \#+\mathrm{V}, \mathrm{i} \rightarrow \mathrm{e} / \mathrm{C}_{-} \#
\end{aligned}
$$

(49) nine

$$
\begin{aligned}
& m u-d g u \\
& \mathrm{mu} \rightarrow \varnothing, \mathrm{d} \rightarrow \varnothing / \mathrm{V}_{-} \mathrm{V}
\end{aligned}
$$

Unlike morpheme loss, the process of Morpheme addition comes into being by adding a separate morpheme in any position of the word. From syntactic-semantic point of view, the addition of an extra morpheme to a word itself gives an extra meaning and grammatical function which was not present at the older word. Deori evidences have shown medial and final morpheme additions. 
The medial and final morpheme additions in Deori have brought changes in the meaning of the lexicon and fulfilled some grammatical functions as well.
(50) $\frac{\text { Gloss }}{\text { die }}$
$\frac{\text { Grierson }}{\text { si-be }} \quad \frac{\text { Deori }}{\text { siruba }}$
/ru/ insertion, $\mathrm{e} \rightarrow \mathrm{a} / \mathrm{C}_{-} \#$
(51) run
jo-me jonoma
/no/ insertion, e $\rightarrow$ a/C_\#
(52) before
dugong
dugojuho
/juho/ addition, /y/ deletion
(53) up
picha
pic $^{\mathrm{h}}$ oho
$\mathrm{a} \rightarrow \mathrm{o} / \mathrm{C}_{-} \mathrm{C}, / \mathrm{h} \mathrm{o} /$ insertion
(54) tongue

$$
\begin{aligned}
& \text { chi } \\
& \mathrm{c}^{\mathrm{h}} \rightarrow \mathrm{s} / \# \_\mathrm{V}, / \text { li-li } \text { addition }
\end{aligned}
$$
(55) go

$$
\begin{aligned}
& \text { khero } \\
& \mathrm{k}^{\mathrm{h}} \rightarrow \mathrm{k} / \#+\mathrm{V}, \mathrm{o} \rightarrow \mathrm{u} / \mathrm{C}_{-} \mathrm{C}, / \mathrm{ba} / \text { addition }
\end{aligned}
$$

This comparative study of Grierson's data and present Deori data has also brought evidences of vowel shortening into the fore. In this process of vowel shortening and vowel syncope the constraints of avoiding a long vowel or a diphthong in final position and avoiding a vowel in the weak position of a foot can be taken into consideration. In Deori, the examples are phonetically conditioned and shortened in the final position only.
(56) $\frac{\text { Gloss }}{\text { of us/our }}$
$\frac{\text { Grierson }}{\text { jariyo }}$
$\frac{\text { Deori }}{\text { jaro }}$ is $\rightarrow \mathrm{o} / \#$ (shortening) 
(57) of them/their baariyo

baro

$$
\text { io } \rightarrow \text { o/C_\# (shortening) }
$$

On the contrary, in diphthongization process where a monophthong gets diphthongized either by adding another vowel sound with it or shifting to a sequence of two vowel sounds can be represented in the following way: $\mathrm{V} \rightarrow \mathrm{VV}$.

Deori has shown the evidences of this kind of vowel diphthongization in the following where an existing diphthong changes into another diphthong.
(58) $\frac{\text { Gloss }}{\text { child }}$

$$
\begin{aligned}
& \text { Grierson Deori } \\
& \text { mausha moisa } \\
& \mathrm{s}^{\mathrm{h}} \rightarrow \mathrm{s} / \mathrm{V}_{-} \mathrm{V}, \mathrm{au} \rightarrow \text { oi/C_C (diphthongization) }
\end{aligned}
$$

In this particular period of this study, Deori has seen a number of vowel shifting experiences. The Deori sound system has shown the phenomenon of chain shifting where the vowels are either promoted or demoted in a sequential order. In this language the vowel shift seems to be quite regular. All the front and back high vowels are moving down the lower positions (Figure 2) with an exception of front low vowel /a/ which is moving towards back position and the higher position.

$\begin{array}{lll}\text { (59) } \frac{\text { Gloss }}{\text { of him/his }} & \begin{array}{l}\text { Grierson (1903) } \\ \text { biyo } \\ \mathrm{i} \rightarrow \mathrm{a} / \mathrm{C}_{-} \mathrm{V}, \mathrm{o} \rightarrow \mathrm{o}^{\prime} \mathrm{V}_{-} \#\end{array} & \frac{\text { Deori (2009) }}{\text { baio }} \\ & \begin{array}{l}\text { guri } \\ \mathrm{u} \rightarrow \mathrm{o} / \mathrm{C}_{-} \mathrm{C}\end{array} & \text { gora } \\ & & \\ \text { (60) horse } & \text { dikemuru } & \text { dekumuru } \\ & \mathrm{i} \rightarrow \mathrm{e} / \mathrm{C}_{-} \mathrm{C} & \end{array}$


(62) sit

$$
\begin{array}{ll}
d u d u-b e & \text { duduba } \\
\mathrm{e} \rightarrow \mathrm{a} / \mathrm{C}_{-} \# &
\end{array}
$$

(63) thou

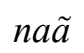

กว

$$
\tilde{\mathrm{a}} \rightarrow \mathrm{o} / \#
$$

Figure 2. Vowel Shift in Deori

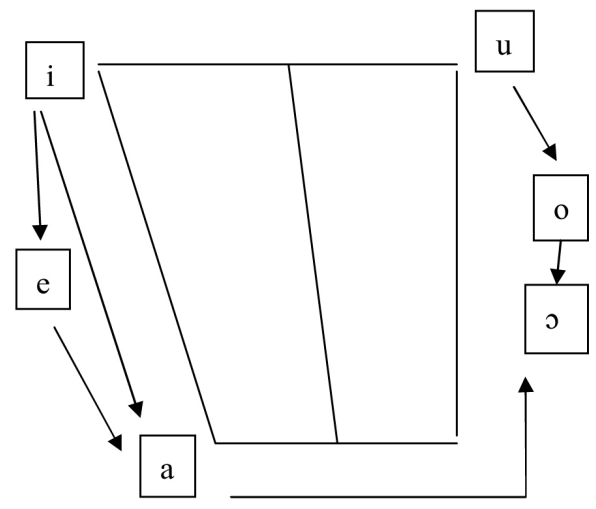

Another important linguistic occurrence is the borrowing of lexical items and loanwords from a dominant language. In the present study, Assamese language plays the role of the dominant language and Deori has accepted abundance of loan words and borrowed lexemes profusely from Assamese. Although, borrowing as such is not harmful to any language, rather it enriches the body of lexicon, yet, excessive borrowing might lead to the phenomenon called 'negative borrowing.' This has certainly have implications on the speakers' habit and eventually bring in changes to the languages. Muysken, in his differentiation of Code Switching and Lexical Borrowing, opines that lexical borrowing involves "formatives ... inserted into an alien word structure. The structure of the word is alien because it behaves externally like an element from the host language." (Muysken 1995: 189, cited in Dako 2002: 
2). But, loan words are always 'code mixing.' Because of the excessive contact between two languages, usually the dominant language intrudes over the dominated language. Deori shows excessive borrowed words from Assamese language which eventually making the speakers to lose many lexical items from its vocabulary. Below, there are some examples of lexical borrowings in Deori from its surrounding dominant language Assamese.
$\underline{\text { Gloss }}$
$\underline{\text { Grierson }}$
$\underline{\text { Deori }}$
a. iron
shing
loha
b. but
kintu
kintu
c. if
jati
jodi
d. star
jethi
tora
e. tongue
chi
jiba
f. devil
bhutu
$b^{\text {h }}$ ut

Following is a diagram which shows the various processes involve in borrowing and loan words and how they are being nativized in their lexicon.

Figure 3. Processes Involved in Borrowing

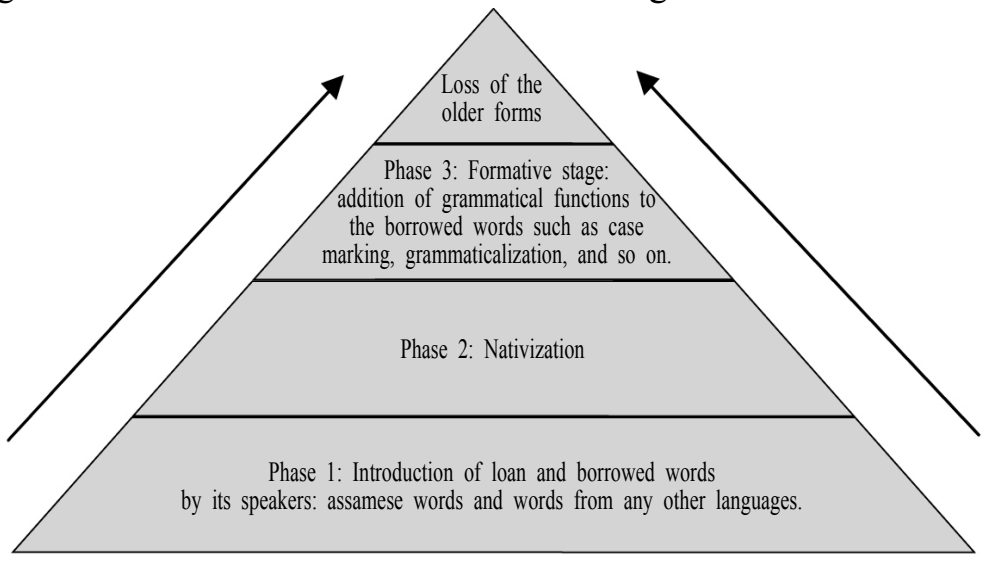




\section{Conclusions}

The above data analyses have significantly proved that within the span of last hundred years, Deori language has undergone colossal amount of sound changes. Although certain changes are inevitable, some changes especially enormous use of borrowing words, losing of numeral system, and so on really alarm us that this language is rightly heading towards the direction of language endangerment situation. Change in a language is unavoidable; in fact, there is no language which has been remained unchanged for centuries. But, Deori has lost a huge amount of lexical items over the time. For example, out of those hundred tested words taken from Grierson's word list, on an average, $80 \%$ words have undergone phonetic changes in this period of hundred years. Although, there are some demerits in the word list and the data presented by Grierson such as unclear Romanization, lack of IPA symbols, diacritic marks, and so on, it could still enable us to make some holistic judgment which are indeed immensely beneficial for language typologists. For example, from the analyses itself, we can conclude that the Deori number system is almost on the verge of extinction. Only a few aged people could retrieve those numbers with the help of written documents. The influence of Assamese velar fricative $/ x /$ has been also seen in many instances of sound changes. Moreover, complete lexical shift from the older lexemes to new lexemes has been one of the dominant phenomena of sound changes during the last hundred years in Deori. Borrowings are also fast replacing many vocabularies in this language and impacting negatively. Most importantly, Deori has lost aspiration in many words in the last hundred years. Morpheme addition, Morpheme elision, vowel shortening, vowel shift, and so on have also been in operation in the last hundred years and inflicted a huge amount of sound changes in Deori. 


\section{References}

Beck, D. 2006. Aspects of the Theory of Morphology. Berlin: Walter de Gruyter.

Brown, W. 1895. An Outline Grammar of the Deuri-Chutiya Language Spoken in Upper Assam. Shillong: The Assam Secretariat Printing Office. Available at URL $<$ http://home.us. archive.org/stream/anoutlinegramma00browgoog/anoutlinegram ma00browgoog_djvu.txt>.

Campbell, L. 2004. Historical Linguistics: An Introduction. Edinburgh: Edinburgh University Press.

Dako, K. 2002. Code Switching and Lexical Borrowing: Which is What in Ghanaian English? English Today 18.3, 48-54.

Fischer, R. 1998. Lexical Change in Present Day English-A Corpus Based Study of the Motivation, Institutionalization, and Productivity of Creative Neologisms. Tübingen: G. Narr.

Grierson, G. (ed.) 1903. Linguistic Survey of India: Tibeto-Burman Family. Delhi: Low Price Publication.

Hock, H. 1991. Principles of Historical Linguistics. Berlin: Walter de Gruyter.

Hock, H. \& B. Joseph. 1996. Language History, Language Change, and Language Relationship. Berlin: Walter de Gruyter.

Kikuchi, S. 1997. A Correspondence-Theoretic Approach to Alternating Diphthongs in Spanish. Journal of Linguistic Science Tohoku University 1, 39-50.

Klopfenstein, M. 2006. Phonetic Implementation of Phonological Categories: The Case of Contextual and Contrastive Vowel Nasalization in Ottawa. M.A. Thesis. Wayne State University. Labov, W. 1981. Resolving the Neogrammarian Controversy. Language 57.2, 267-308. . 1994. Principles of Linguistic Change: Internal Factors.

New York: John Wiley and Sons.

. 2001. Principles of Linguistic Change: Social Factors. 
Malden and Oxford: Blackwell.

Lehrer, J. 1996. Identifying and Interpreting Blends. Cognitive Linguistics 7.4, 259-290.

Luce, R. et al. 1990. Foundations of Measurement: Representation, Axiomatization, and Invariance. San Diego, CA \& London: Academic Press.

Osthoff, H. \& K. Brugmann. 1878/1967. Preface to Morphological Investigations in the Sphere of the Indo-European Languages Volume I. In W. Lehmann (ed.), A Reader in NineteenthCentury Historical Indo-European Linguistics 197-209. Bloomington, IN: Indiana University Press. 